\title{
Study on Carbon Emission Estimation and Reduction Methods of Electric Vehicle Battery Packs in Whole Life Cycle
}

\author{
ChengshanX $\mathrm{u}^{1, \mathrm{a}}$, Dongxiang Yan ${ }^{1, \mathrm{~b}}$, Fachao Jiang ${ }^{1, \mathrm{c}^{*}}$ \\ ${ }^{1}$ College of Engineering, China Agricultural University, Beijing 100083, China. \\ axuchsh_2013@sina.cn,'byan_dongxiang@126.com, 'jiangfachao@163.com
}

Keywords: Carbon emission, electric vehicle battery packs, whole life cycle.

\begin{abstract}
It is meaningful for evaluating carbon emission of battery packs of electric vehicles in their whole life cycle. In this paper, we give a new method to estimate carbon emission of battery packs in their life cycle. The method aims at evaluating carbon emission of different kinds of battery packs and their recycle methods reasonably, which can be useful for energy conservation and emission reduction of battery packs and their recycle methods as well.
\end{abstract}

\section{Introduction}

With the increasingly serious environment problems and energy crisis, developing electric vehicles (EVs) has become a vital approach to realizing energysafetyand sustanable development. Automobile industry plays a great role in national economic system and the healthy development of it mostly relies on the progress and industrialization of technologies of EVs. In the recent years, the main automobile producing countries in the world have taken EVs as an important strategy for improving industrial competitiveness and maintaining sustainable development of social economics. Governments of these countries also provided policies to encourage developing EV industry.

As an essential approach to solve energy crisis and environment pollution problem, it is important to apply the theory of whole life cycle to EV battery packs. Through the theory, model of carbon emission in whole life cycle of EV battery packs was built to analyze battery packs'energy consumption and emissions. The research provides a solution to optimal the design of battery packs [1].

\section{Carbon emission model of battery packs}

Battery packs of EVs usually consist of battery box, single batteries, shells of battery components, shells of battery packs, battery management system (BMS). A single battery includes anode, cathode, separator, electrolyte, shell, etc.

The whole cycle life of a battery pack can be divided into three periods: manufacturing, using and recycling $[2,3]$. Each step exists carbon emission. In the first term, carbon emission is caused by energy consumption during manufacturing components of batteries. Carbon emission produced in the second term is mostly caused by electric energy loss during charge and discharge. In the third term, disassembly and dissolution of battery components will consume energy which causes carbon emission. In table 1, different parameters are used to represent carbon emission of different components in different steps. In this table, seven different components of battery packs are taken as example, the table can be extended if there are more components.

The carbon emission $\mathrm{Q}_{\mathrm{j}}$ of each component in different period can be calculated by the following method:

1) Manufacture

$\mathrm{Q}_{\mathrm{Cj}}=\sum_{\mathrm{i}=1}^{\mathrm{n}} \mathrm{t}_{\mathrm{i}} \mathrm{c}_{\mathrm{i}}(1)$

2) Using

$\mathrm{Q}_{\mathrm{wj}}=\mathrm{fQd}$ 
Table 1 Carbon emission in different steps

\begin{tabular}{|c|c|c|c|c|c|c|c|}
\hline \multirow{3}{*}{$\begin{array}{l}\text { Carbon } \\
\text { Emission }\end{array}$} & \multicolumn{7}{|c|}{ Battery Pack } \\
\hline & \multirow{2}{*}{ Box } & \multirow{2}{*}{$\begin{array}{c}\text { Connecting } \\
\text { Lines }\end{array}$} & \multicolumn{5}{|c|}{ Single Battery } \\
\hline & & & $\begin{array}{l}\text { Anode } \\
(\mathrm{g} / \mathrm{kg})\end{array}$ & $\begin{array}{l}\text { Cathode } \\
(\mathrm{g} / \mathrm{kg})\end{array}$ & $\begin{array}{l}\text { Separator } \\
(\mathrm{g} / \mathrm{kg})\end{array}$ & $\begin{array}{c}\text { Electrolyte } \\
(\mathrm{g} / \mathrm{kg})\end{array}$ & $\begin{array}{l}\text { Shell } \\
(\mathrm{g} / \mathrm{kg})\end{array}$ \\
\hline $\begin{array}{c}\text { Manufact-u } \\
\text { ring Step }\end{array}$ & $a_{11}$ & $a_{12}$ & $a_{13}$ & $a_{14}$ & $a_{15}$ & $a_{16}$ & $a_{17}$ \\
\hline Using Step & $a_{21}$ & $a_{22}$ & $a_{23}$ & $a_{24}$ & $a_{25}$ & $a_{26}$ & $a_{27}$ \\
\hline $\begin{array}{c}\text { Recycling } \\
\text { Step }\end{array}$ & $a_{31}$ & $a_{32}$ & $a_{33}$ & $a_{34}$ & $a_{35}$ & $a_{36}$ & $a_{37}$ \\
\hline Total & $\mathrm{Q}_{1}$ & $\mathrm{Q}_{2}$ & $\mathrm{Q}_{3}$ & $\mathrm{Q}_{4}$ & $\mathrm{Q}_{5}$ & $\mathrm{Q}_{6}$ & $Q_{7}$ \\
\hline
\end{tabular}

3) Recycling

$\mathrm{Q}_{\mathrm{Rj}}=\mathrm{d}_{\mathrm{R} 1}-\mathrm{d}_{\mathrm{R} 2}$

In this equation, $Q_{\mathrm{Rj}}$ represents the emission of each different components in recycling, its unit is $\mathrm{g} / \mathrm{kg}$. $\mathrm{d}_{\mathrm{R} 1}$ represents the carbon emission of electric energy or other consumption in recycle process, its unit is $\mathrm{g} / \mathrm{kg}, \mathrm{d}_{\mathrm{R} 2}$ is the carbon emission that can be reduced after recycling, its unit is $\mathrm{g} / \mathrm{kg}$.

The total carbon emission of each component in whole life cycle is:

$Q_{j}=Q_{C j}+Q_{w j}+Q_{R j}$

Thus, the total emission of the battery pack can be concluded as:

$\mathrm{Q}=\sum_{\mathrm{j}=1}^{7} \mathrm{Q}_{\mathrm{j}}$

\section{Optimize Method}

There are various methods to produce and recycle batteries. This thesis assumes that both producing and recycling batteries have two different methods. The network diagram is shown in Fig.1.

In Fig. 1, $\mathrm{a}_{11}$ and $\mathrm{a}_{12}$ represents carbon emission of the two different ways to produce battery box in manufacturing step, $a_{31}$ and $a_{32}$ represents carbon emission of the two different ways to recycle battery box in recycling step. $b_{11}$ and $b_{12}$ represents carbon emission of the two different ways to produce connecting lines in manufacturing step, $b_{31}$ and $b_{32}$ represents carbon emission of the two different ways to recycle connecting lines in recycling step. $c_{11}$ and $c_{12}$ represents carbon emission of the two different ways to produce anode materials in manufacturing step, $c_{31}$ and $c_{32}$ represents carbon emission of the two different ways to recycle anode materials in recycling step. $d_{11}$ and $d_{12}$ represents carbon emission of the two different ways to produce cathode materials in manufacturing step, $d_{31}$ and $d_{32}$ represents carbon emission of the two different ways to recycle cathode materials in recycling step. $\mathrm{e}_{11}$ and $\mathrm{e}_{12}$ represents carbon emission of the two different ways to produce electrolyte materials in manufacturing step, $\mathrm{e}_{31}$ and $\mathrm{e}_{32}$ represents carbon emission of the two different ways to recycle electrolyte materials in recycling step. $f_{11}$ and $f_{12}$ represents carbon emission of the two different ways to produceseparator materials in manufacturing step, $\mathrm{f}_{31}$ and $\mathrm{f}_{32}$ represents carbon emission of the two different ways to recycle separator materials in recycling step. $\mathrm{g}_{11}$ and $\mathrm{g}_{12}$ represents carbon emission of the two different ways to produce shell materials in manufacturing step, $\mathrm{g}_{31}$ and $\mathrm{g}_{32}$ represents carbon emission of the two different ways to recycle shell materials in recycling step.

Take the battery box as an example. Different ways to produce battery box lead to different carbon emission. Generally, the method which has less carbon emission is considered as more environmental-friendly and better economic benefitone.Thus, selection of the least carbon emission method is significant for battery producers. 


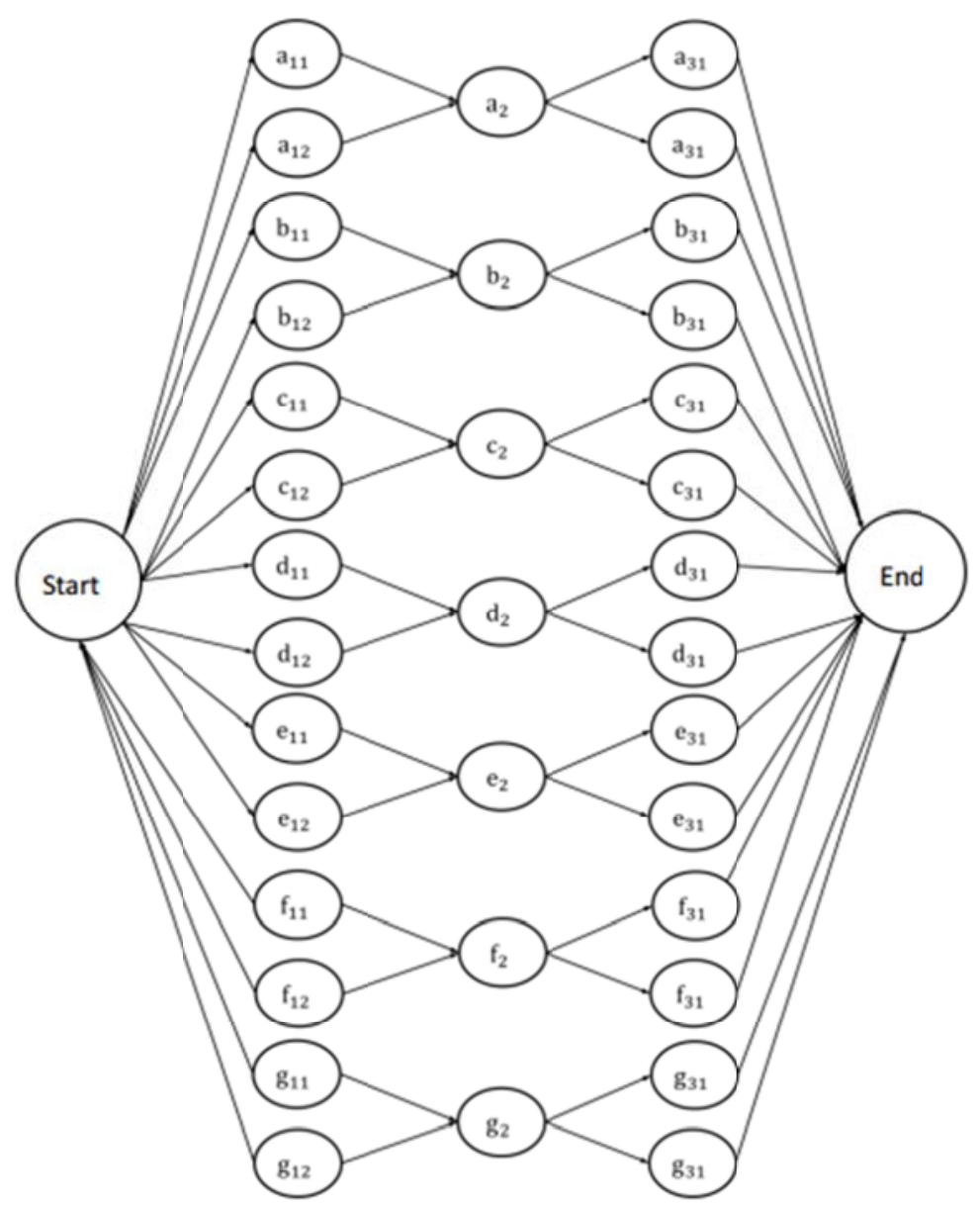

Fig. 1 Network chart

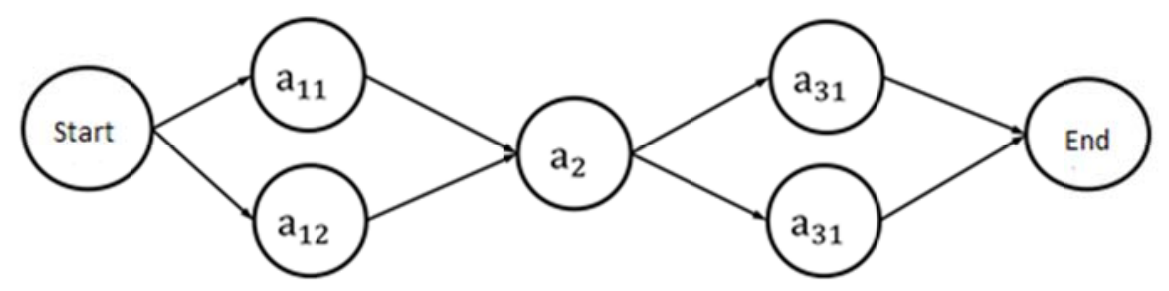

Fig. 2 Flow chart

The optimal function of carbon emission in manufacturing step can be described as:

$\mathrm{Q}_{\mathrm{C} 1}=\min \left\{\mathrm{a}_{11}, \mathrm{a}_{12}\right\}$

In the using step, reason for carbon emission is simple if we assume there is only one using method.

In recycling step, the optimal function is:

$\mathrm{Q}_{\mathrm{R} 1}=\min \left\{\mathrm{a}_{31}, \mathrm{a}_{32}\right\}$

So the carbon emission of battery box in whole life cycle can be optimized by the aforementioned functions.

As the methods of manufacturing or recycling components of battery packs could be various, mostly more than two, we extend the optimize model as follows. If number of methods of manufacturing is $\mathrm{m}$, and recycling is $\mathrm{n}$, then the optimize calculation of carbon emission can be described as:

$\mathrm{Q}_{\mathrm{C}}^{\prime}=\sum_{\mathrm{a} \leq \mathrm{A} \leq \mathrm{g}} \min \{\mathrm{A} 11, \mathrm{~A} 12, \ldots \mathrm{A} 1 \mathrm{~m}\}$

$\mathrm{Q}_{\mathrm{R}}^{\prime}=\sum_{\mathrm{a} \leq \mathrm{A} \leq \mathrm{g}} \min \{\mathrm{A} 11, \mathrm{~A} 12, \ldots \mathrm{A} 1 \mathrm{n}\}$

$A=a, b, c, d, e, f, g$ represents seven different components.

The optimized total of carbon emission of a battery pack in whole life cycle is: 
$\mathrm{Q}=\mathrm{Q}_{\mathrm{C}}^{\prime}+\mathrm{Q}_{\mathrm{W}}+\mathrm{Q}_{\mathrm{R}}^{\prime}$

In order to analyze different influences of each battery pack components, method of the simple factor analysis of variance is used to confirm the main influence factor and reduce the value of Q.

For better optimizing carbon emission, table 1 is simplified as an array (row is $\mathrm{i}$, column is $\mathrm{j}$ ):

$\left[\begin{array}{lllllll}\mathrm{a}_{11} & \mathrm{a}_{12} & \mathrm{a}_{13} & \mathrm{a}_{14} & \mathrm{a}_{15} & \mathrm{a}_{16} & \mathrm{a}_{17} \\ \mathrm{a}_{21} & \mathrm{a}_{22} & \mathrm{a}_{23} & \mathrm{a}_{24} & \mathrm{a}_{25} & \mathrm{a}_{26} & \mathrm{a}_{27} \\ \mathrm{a}_{31} & \mathrm{a}_{32} & \mathrm{a}_{33} & \mathrm{a}_{34} & \mathrm{a}_{35} & \mathrm{a}_{36} & \mathrm{a}_{37}\end{array}\right]$

The following equations can be calculated:

$$
\begin{aligned}
& \mathrm{C}_{\mathrm{T}}=\frac{\left(\sum_{1}^{\mathrm{i}} \sum_{1}^{\mathrm{j}} \mathrm{a}_{\mathrm{ij}}\right)^{2}}{\mathrm{i} * \mathrm{j}} \\
& \mathrm{S}_{\mathrm{T}}=\sum_{1}^{\mathrm{i}} \sum_{1}^{\mathrm{j}} \mathrm{a}_{\mathrm{ij}}^{2}-\mathrm{C}_{\mathrm{T}} \\
& \mathrm{S}_{\mathrm{A}}=\frac{\sum_{1}^{\mathrm{i}}\left(\sum_{1}^{\mathrm{j}} \mathrm{a}_{\mathrm{ij}}\right)^{2}}{\mathrm{j}}-\mathrm{C}_{\mathrm{T}} \\
& \mathrm{S}_{\mathrm{B}}=\frac{\sum_{1}^{\mathrm{j}}\left(\sum_{1}^{\mathrm{i}} \mathrm{a}_{\mathrm{ij}}\right)^{2}}{\mathrm{i}}-\mathrm{C}_{\mathrm{T}} \\
& \mathrm{S}_{\mathrm{e}}=\mathrm{S}_{\mathrm{T}}-\mathrm{S}_{\mathrm{A}}-\mathrm{S}_{\mathrm{B}}
\end{aligned}
$$

Then calculate the degree of freedom of each factor:

$$
\begin{aligned}
& \mathrm{f}_{\mathrm{T}}=\mathrm{i} \cdot \mathrm{j}-1 \\
& \mathrm{f}_{\mathrm{A}}=\mathrm{i}-1 \\
& \mathrm{f}_{\mathrm{B}}=\mathrm{j}-1 \\
& \mathrm{f}_{\mathrm{e}}=\mathrm{f}_{\mathrm{T}}-\mathrm{f}_{\mathrm{A}}-\mathrm{f}_{\mathrm{B}}
\end{aligned}
$$

The calculation before can be concluded as table 2 .

Table 2. Analysis of variance table

\begin{tabular}{|l|l|l|l|l|l|}
\hline $\begin{array}{c}\text { Vary } \\
\text { Reason }\end{array}$ & \multicolumn{1}{|c|}{$\begin{array}{c}\text { Quadratic } \\
\text { Sum }\end{array}$} & $\begin{array}{c}\text { Degree of } \\
\text { Freedom }\end{array}$ & Variance & \multicolumn{1}{|c|}{$\mathrm{F}_{0}$} & $\mathrm{~F}(0.05)$ \\
\hline $\mathrm{A}$ & $\mathrm{S}_{\mathrm{A}}$ & $\mathrm{f}_{\mathrm{A}}$ & $\mathrm{S}_{\mathrm{A}} / \mathrm{f}_{\mathrm{A}}$ & $\mathrm{F}_{0 \mathrm{~A}}=\left(\mathrm{S}_{\mathrm{A}} / \mathrm{f}_{\mathrm{A}}\right) /\left(\mathrm{S}_{\mathrm{e}} / \mathrm{f}_{\mathrm{e}}\right)$ & $\mathrm{F}_{\mathrm{A}}=\mathrm{F}_{1-\mathrm{a}}\left(\mathrm{f}_{\mathrm{a}}, \mathrm{f}_{\mathrm{e}}\right)$ \\
\hline $\mathrm{B}$ & $\mathrm{S}_{\mathrm{B}}$ & $\mathrm{f}_{\mathrm{B}}$ & $\mathrm{S}_{\mathrm{B}} / \mathrm{f}_{\mathrm{B}}$ & $\mathrm{F}_{0 \mathrm{~B}}=\left(\mathrm{S}_{\mathrm{B}} / \mathrm{f}_{\mathrm{B}}\right) /\left(\mathrm{S}_{\mathrm{e}} / \mathrm{f}_{\mathrm{e}}\right)$ & $\mathrm{F}_{\mathrm{B}}=\mathrm{F}_{1-\mathrm{a}}\left(\mathrm{f}_{\mathrm{B}}, \mathrm{f}_{\mathrm{e}}\right)$ \\
\hline $\mathrm{e}$ & $\mathrm{S}_{\mathrm{e}}$ & $\mathrm{f}_{\mathrm{e}}$ & $\mathrm{S}_{\mathrm{e}} / \mathrm{f}_{\mathrm{e}}$ & & \\
\hline Total & $\mathrm{S}_{\mathrm{A}}+\mathrm{S}_{\mathrm{B}}+\mathrm{S}_{\mathrm{e}}$ & $\mathrm{f}_{\mathrm{A}}+\mathrm{f}_{\mathrm{B}}+\mathrm{f}_{\mathrm{e}}$ & & & \\
\hline
\end{tabular}

With regard to $\mathrm{A}$ :

If $\mathrm{F}_{0 \mathrm{~A}}>\mathrm{F}_{\mathrm{A}}$, then we consider that there is obvious significance between each mean value.

If $\mathrm{F}_{0 \mathrm{~A}} \leqq \mathrm{~F}_{\mathrm{A}}$, then we consider that there is no significance between each mean value.

With regard to $\mathrm{B}$ :

If $F_{0 B}>F_{B}$, then we consider that there is obvious significance between each mean value.

If $F_{0 B} \leqq F_{B}$, then we consider that there is no significance between each mean value.

The obvious significant factor can be confirmed by aforementioned results and used to control carbon emission. The whole process is described as Fig.3.

\section{Conclusions}

This paper put forward a new way to estimate carbon emission and found reduction methods of electric vehicle battery packs in whole life cycle. According to the characteristics of life cycle, battery packs were analyzed systematically. The whole life cycle of battery packs was first divided into three steps and the battery packs were seen as small components. Several equations were proposed to describe the carbon emission of each step. Then, optimization methods were used to verify which component would be the obviously significant factor for carbon emission and improvement methods would be raised according to analysis. 


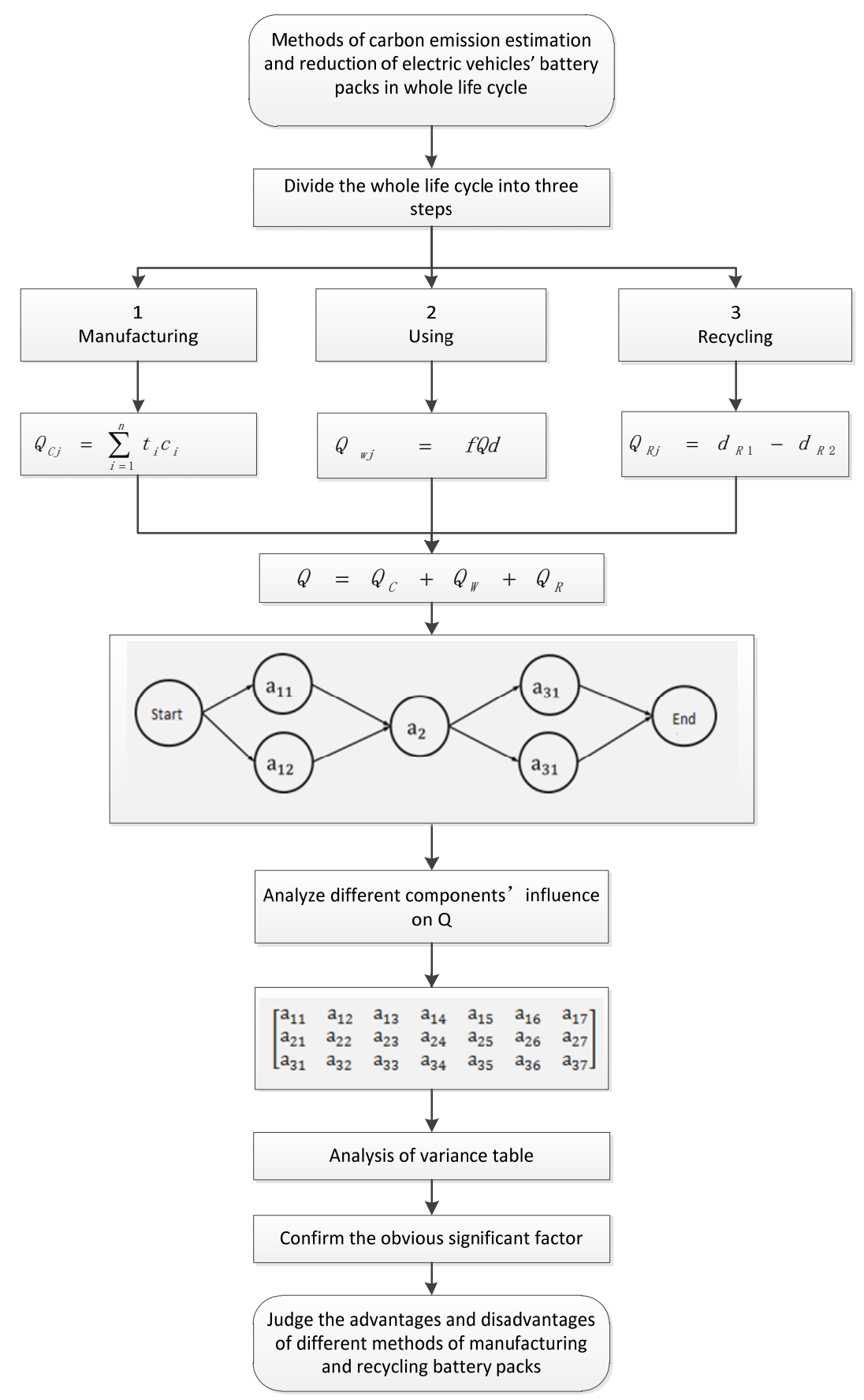

Fig. 3 Process diagram

\section{Acknowledgments}

This work was supported by Beijing Natural Science Foundation (No. 3153026). Thanks for the support of BNSF.

\section{References}

[1] YajunGe, Study on Life-cycle Assessment Methods for Waste Secondary Battery, Environmental Sanitation Engineering, 2008,16(02):46-48.

[2] DaidiHuang, DingguoXia, Application of Life Cycle Assessment in Cobalt OxideProduct ion, Environmental Science \& Technology, 2007,30(07):56-58.

[3] Wei Zhou, Guowei $\mathrm{Wu}$, Modeling of recycling and its circular economy based on battery life cycle, Recyclable Resources and Cyclular Economy, 2006(03):35-38. 